\title{
Male External Genital Injuries; Pattern of Presentation and Management at the Jos University Teaching Hospital
}

\author{
Ofoha C.G.,Shu'aibu S.I., Akpayak I.C.,Dakum N.K., Ramyil V.M. \\ Division Of Urology, Department Of Surgery, Jos University Teaching Hospital, Jos, Nigeria.
}

\begin{abstract}
:
Background: Generally, severe injuries of the male external genitalia are rare because of the location and mobility of the penis and scrotum. Although injuries to the external genitalia are typically not in and of themselves life threatening, they are commonly associated with other potentially life-threatening injuries. This study is to evaluate the mechanism and type of genital injuries, other associated injuries and management of genital injuries.

Methodology: This study was carried out at the Jos University Teaching Hospital, Jos between January 2010 and June 2014.All male patients presenting with external genital trauma at the accident and emergency unit were initially resuscitated by the emergency room team using the ATLS protocol, who then invited the urologist to take over the management. The patients were evaluated for aetiology/ mechanism of injury, type of external genital injury and associated injuries. Modality of treatment was also assessed.

Results: Twenty one individuals with external genital trauma were enrolled into the study. The mean age of the patients was 30.62years. There were different mechanisms for the injuries. Gunshot constituted the highest mechanism (n=12) 57.1\%. Three patients had blunt injuries (14.3\%), while $85.7 \%$ had penetrating genital injuries.Ten patients had penile injuries representing $47.6 \%$. Six patients representing $28.6 \%$ had scrotal injuries. Of these $28.6 \%, 5$ patients, representing $83.3 \%$ had testicular rupture with one patient having bilateral testicular rupture. Five patients had combined penoscrotal injury representing $23.8 \%$. Ten patients (47.6\%) had associated injuries. All the patients had surgical intervention.

Conclusion: The genital organs are vital in the reproductive process as well as psychological well being of the individual, hence it becomes imperative for prompt and adequate assessment and treatment of injuries of the system.
\end{abstract}

Key words: Male genital injuries, penile, scrotal, penoscrotal.

\section{Introduction}

Generally, severe injuries of the external male genitalia are rare because of the location and mobility of the penis and scrotum[1]. Although injuries to the external genitalia are typically not in and of themselves life threatening, they are commonly associated with other potentially life-threatening injuries (for example, to abdomen, pelvis or groin) [2]. Traumatic injuries to the genitourinary tract are seen in $2.2-10.3 \%$ of patients admitted to hospitals [3], [4], [5]. Of these injuries, between one-third and two-thirds of cases are associated with injuries to the external genitalia [3].

Genitourinary trauma is seen in all age groups, most frequently in males between 15 and 40 years of age. However, $5 \%$ of trauma patients are less than 10 years [6].

The penis, scrotum, and testes are all vulnerable to both blunt and penetrating traumatic injury. Testicular injuries include contusions or rupture from blunt trauma. Scrotal trauma often includes penetrating wounds, burns, or avulsions. The penis is subject to diverse injuries, including zipper injuries, fractures (rupture of the corpus cavernosum), amputations, or strangulations. External genitalia are at risk for injury from human or animal bites [7] as well as missiles.

Genital injuries are significant because of their association with injuries to major pelvic and vascular organs that result from both blunt and penetrating mechanisms, and the chronic disability resulting from penile and scrotal trauma. Because trauma is predominantly a disease of young persons, genital injuries may profoundly affect health-related quality of life and contribute to the burden of disease related to trauma [8],[9].

Beside primary wound treatment and maintenance or recovery of function (erection, fertility, testicular hormone secretion and micturition), satisfactory cosmetic results are also important in the surgeon's efforts.

This study is to evaluate the mechanism and type of genital injuries, other associated injuries and management of genital injuries. 


\section{Methodology}

This study was carried out in the Jos university teaching hospital, Jos between 2010 and 2014.All male patients presenting with external genital trauma in the accident and emergency unit were initially resuscitated by the emergencyroom team using the ATLS protocol, who then invited the urologist to take over the management.

The patients were evaluated for aetiology/ mechanism of injury, type of external genital injury and associated injuries. Modality of treatment was also assessed.Patients were followed up in the clinic.

\section{Results}

The study was conducted at the Jos University Teaching Hospital; Jos. Twenty one individuals with external genital trauma were enrolled into the study from January 2010 to June 2014.

The mean age of the patients was $30.6 y e a r s$. The youngest was a 12 month old infant with dog bite injury while the oldest was a 73 year old man with penoscrotal amputation as a result of ritual attack.

There were different mechanisms for the injuries. Gunshot constituted the highest mechanism $(n=12) 57.1 \%$. Other mechanisms made up the remaining $42.9 \%$.

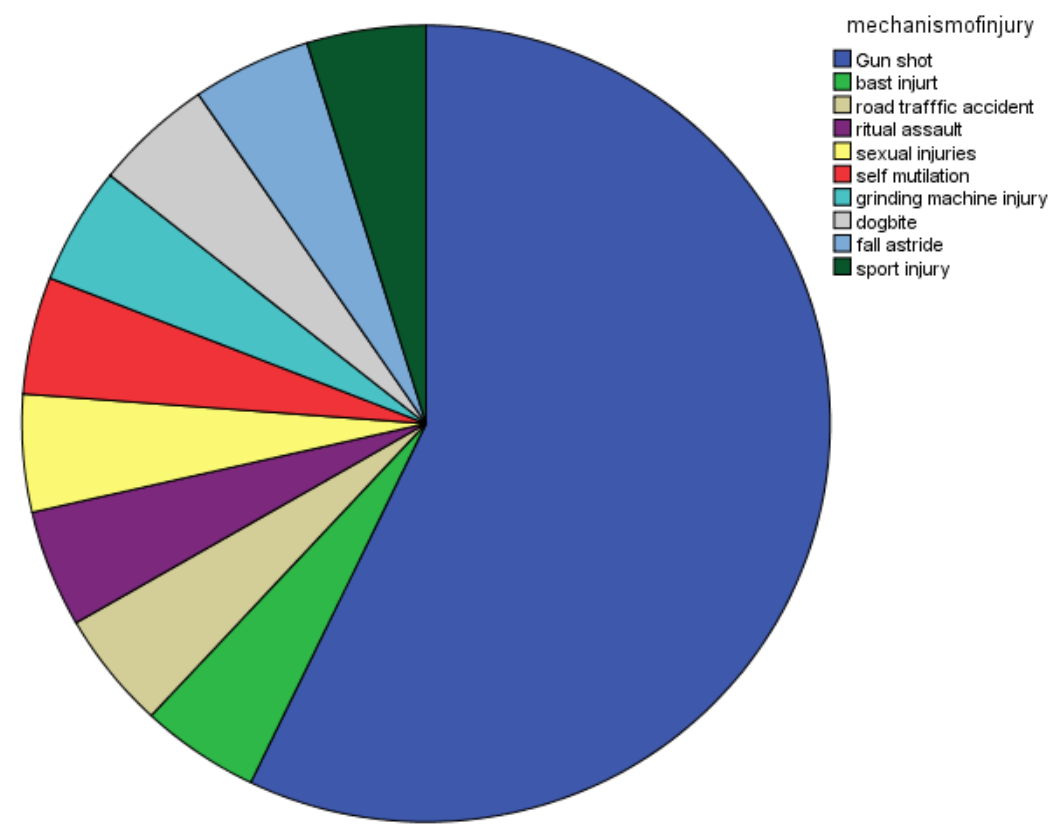

Fig 1: distribution of the mechanism of injury.

Three patients had blunt injuries (14.3\%), while $85.7 \%$ had penetrating genital injuries. Gunshot injuries accounted for $57.1 \%$ of the injuries. Ten patients had penile injuries representing $47.6 \%$. Six patients representing $28.6 \%$ had scrotal injuries. Of these $28.6 \%, 5$ patients, representing $83.3 \%$ had testicular rupture with one patient having bilateral testicular rupture. Five patients had combined penoscrotal injury representing $23.8 \%$ while oneout of these patients had penoscrotal amputation. 


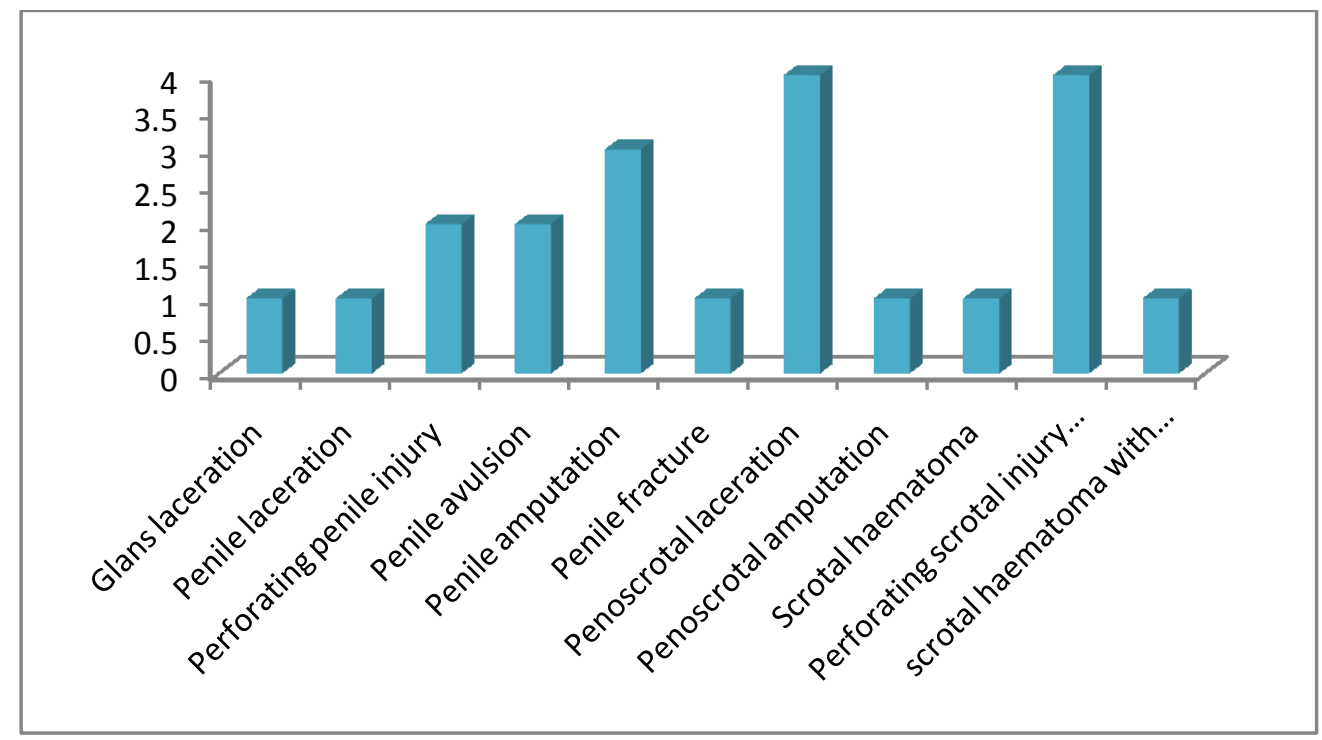

Fig 2: distribution of types of genital injuries.

Ten patients (47.6\%) had associated injuries. Thigh laceration and urethral injuries accounted for $40 \%$ and $33.3 \%$ respectively while femoral fracture and pelvic fracture accounted for $20 \%$ and $6.7 \%$ respectively.

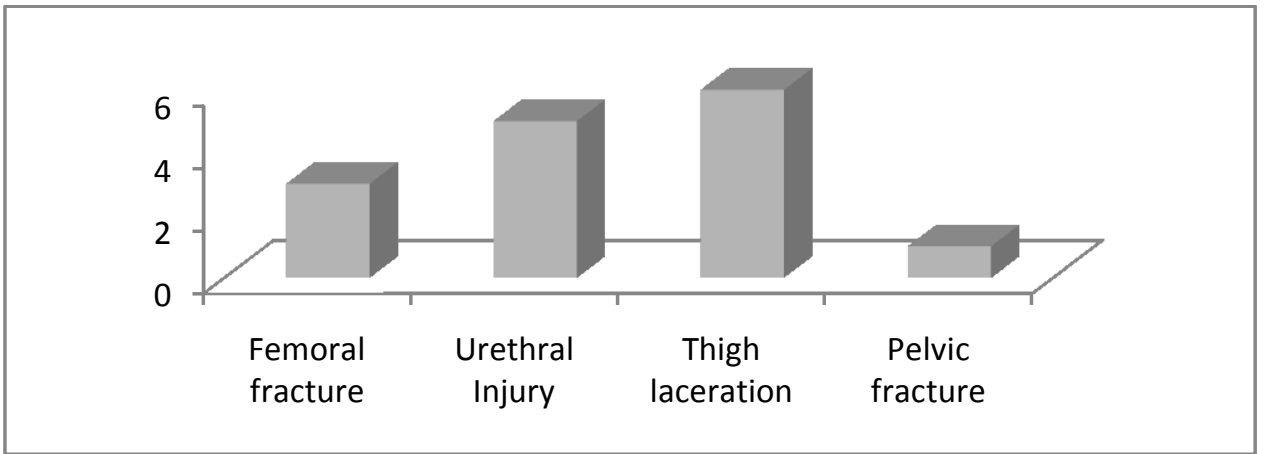

Fig 3: distribution of associated injuries.

Table 1: Type of Surgical Intervention

\begin{tabular}{lcl}
\hline Type of Treatment & Number of Patients & Percentage \\
\hline Penile Exploration & 3 & $14.3 \%$ \\
Penile stump Refashioning and urethrostomy & 3 & $14.3 \%$ \\
Scrotal exploration and orchidectomy & 4 & $19.0 \%$ \\
Scrotal exploration and testicular repair & 2 & $9.6 \%$ \\
$\begin{array}{l}\text { Debridement and delayed wound closure } \\
\text { Debridement and delayed reconstruction }\end{array}$ & 4 & $19.0 \%$ \\
(urethroplasty) & 5 & $23 \%$ \\
\end{tabular}

\section{Discussion}

Proper management of genital trauma requires information about the mechanism of injury, example animals, vehicles and weapons (stab, knife, gun, etc.) in order to estimate the injury and potential risk of associated lesions.

Injuries of the male external genitalia, affects young men commonly. These have been documented by different studies. Lee et al, in a 10 years review of patients with trauma to the male genital organ, recorded a mean age of 27.8 years [9] while Ahmed et al recorded a mean age of 28( \pm 3.2$)$ [10]. In this study the mean age was 30.6 years which is similar to the findings of other investigators.

The mechanism of injuries affecting the male external genitalia is not consistent with any particular pattern. In the study by Ahmed et al [10], road traffic accident and gunshot accounted for $68 \%$ and $16 \%$ of injuries respectively while Alicia et al [11] showed that $79 \%$ of the injuries were due to gunshot.In this study there were variety of mechanisms, blunt trauma accounted for $9.5 \%$ while penetrating trauma accounted $90.5 \%$. 
Overall gunshot injuries accounted for $57.1 \%$. The high rate of gunshot injuries can be attributed to the civil crisis and proliferation of arms which have bedevilled the city for some years now.

In this study, the bulk of the patients had penile injuries (47.6\%). This is similar to the findings by Bertini et al [12], who recorded $60 \%$ penile injuries in a ten year series looking at the etiology and management of genital injuries.

The patients with penetrating, perforating and avulsive penile injuries had penile exploration. In this study, these injuries resulted from gunshot. Conservative debridement of penetrating injuries to the external genitalia was emphasized. The goal was to preserve enough tissue for secondary reconstruction, especially for the patients with associated urethral injury. However, Corporal injuries were repaired primarily with absorbable sutures. This protocol was used by Kunkle et al [13] in managing gunshot injuries to the external genitalia.

Penile 'fracture', or more specifically, rupture of the corpus cavernosum, is an uncommon and underreported injury [14], [15]. We recorded one case following sexual manipulation of the erect penis. He subsequently had penile exploration and repair of the corpora. Surgical exploration and repair of suspected penile fracture gives better outcomes [16], [17]. Fargany et al [18] found that none of their 26 patients treated by primary exploration and repair had persistent haematoma, angulation or plaque formation.

Penile amputation is a rare injury. We recorded three cases caused by grinding machine and self mutilation. Though rare, there have been reports of grinding machine injuries in this part of the world [19], [10].Self-mutilation of the external genitalia has also been reported in psychotic patients and transsexuals [20].Preservation of the severed penis should be sought whenever possible. The amputated segment should be wrapped in saline-soaked gauze and placed in a sealed sterile bag; the bag containing the protected penis is then placed in an ice-slush bath, ensuring that the ice is not in direct contact with the penile skin [21]. The penis should be reimplanted within the first 24 hours after injury. The patients in this study presented late and the severed penis was not properly preserved. Hence the penis wasn't viable. No attempt at reimplantation was made. They all had refashioning of the penile stump and urethrostomy.

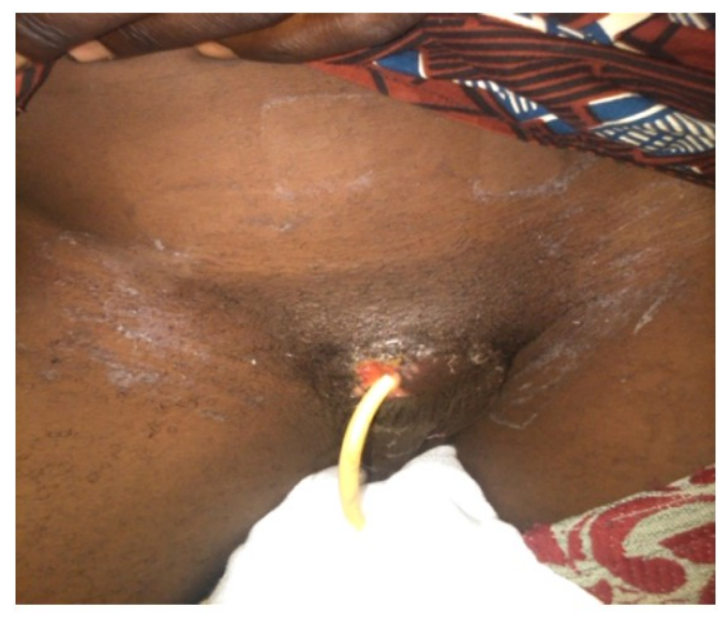

Figure 4.Penile amputation from self genital mutilation.

Patients with scrotal and testicular injuries were promptly explored. In patients with large haematomas without testicular injury, the haematomas were promptly evacuated, however those with testicular rupture, the injured testis was irrigated copiously. Extruded or necrotic seminiferous tubules were debrided, and the tunica albuginea was closed with a running absorbable suture. In one patient who had bilateral testicular injury, tunica vaginalis was used to reconstruct the tunica albuginea of the apparently viable testis. Using this protocol, two (33.3\%) out of the six testicular injuries were salvaged while the remaining four (66.7\%) had orchidectomy. In cases where orchidectomy was performed, there wasn't enough testicular tissue to be approximated.These injuries mostly resulted from high velocity gunshot trauma.

Cass et al [22] recommended prompt drainage of large haematoceles to prevent infectious complications and to prevent prolonged pain, disability and ischaemia of the testis from compression while conservative management can be applied in the management of stable scrotal haematomas and contusions with ice, rest and elevation. However when testicular rupture is suspected prompt surgical intervention is advised in an effort to avoid untoward outcomes, e.g. testicular loss, infection, chronic pain, infertility and altered selfimage [23]. 

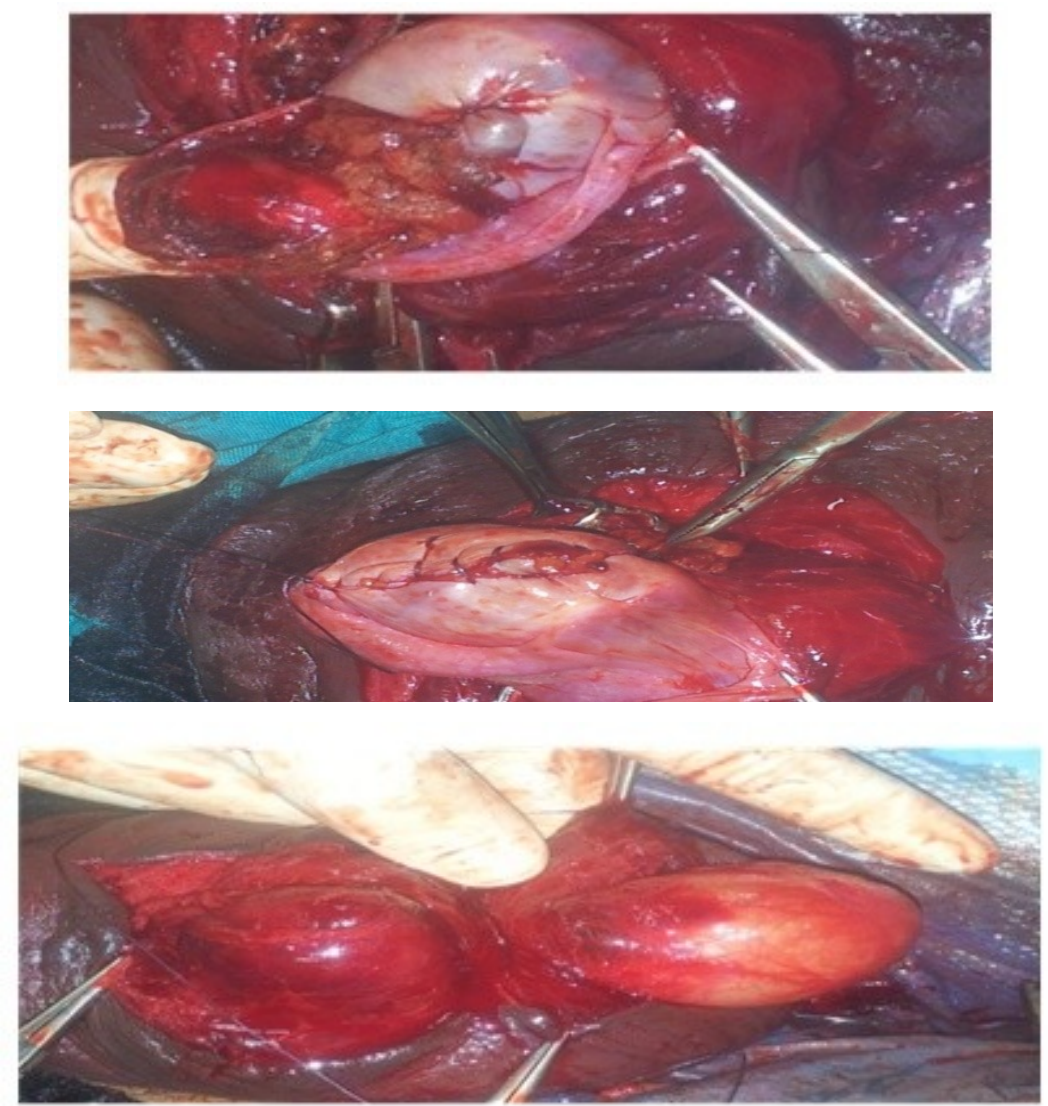

Figure 5:Testicular rupture following high velocity gunshot injury. The patient had scrotal exploration, debridement and testicular repair.

Ten patients (47.6\%) had associated injuries. Ahmed et al [10] in their study, associated injuries were seen in $41 \%$ of the cases. These were mostly to organs adjacent to the genitalia. In this study, musculoskeletal injuries and urethral injuries were commonly encountered. Injuries of the musculoskeletal system were managed in conjunction with the orthopaedics and trauma surgeons while patient with urethral injuries had urethroplasty. The urethroplasties were secondary procedures after initial wound debridement. Patients with avulsive urethral injury from high velocity gunshot had multiple staged procedures.
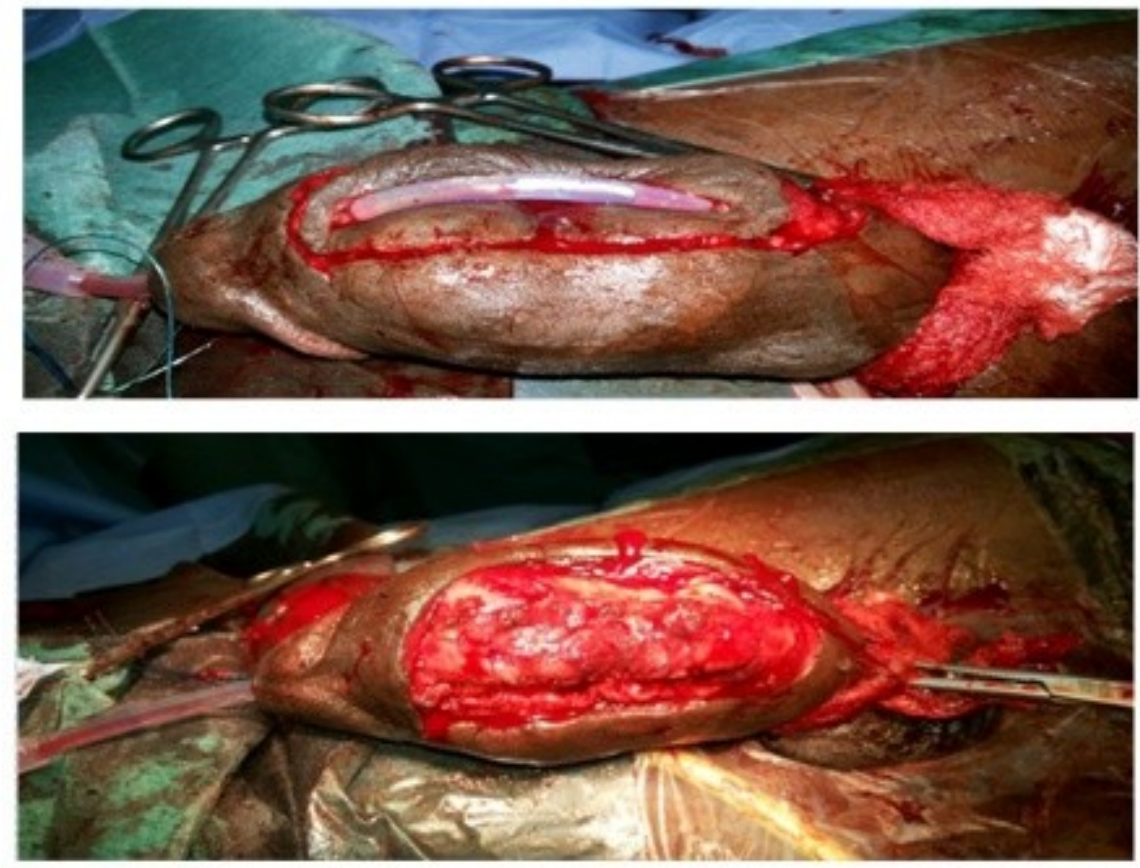


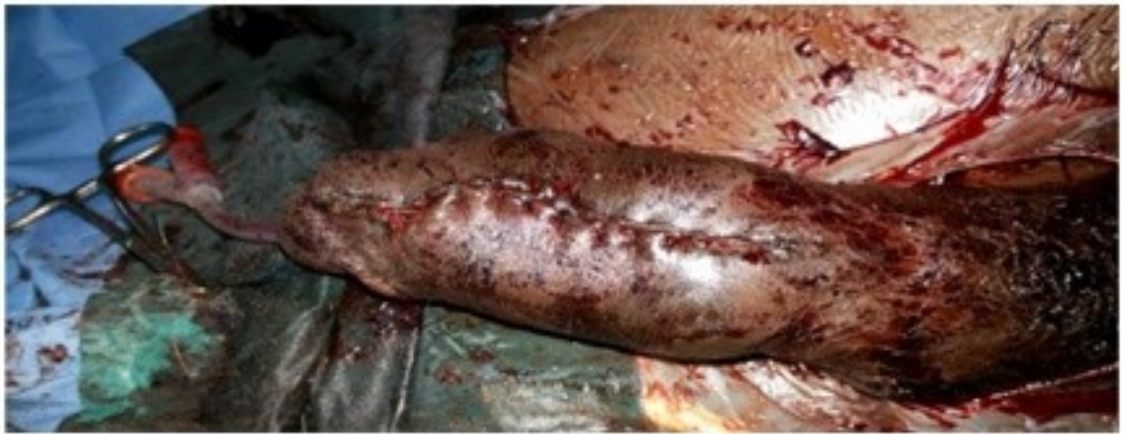

Figure 6: Second stage urethroplasty for high velocity gunshot injury of the ventral aspect of the penis with urethral avulsion.

\section{Conclusion}

The male external genitalia are at risk from diverse forms of trauma. Prompt assessment and surgical intervention is the key to proper management. Public enlightenment on the preservation and transportation of amputated penis will increase the salvage rate.

\section{Reference}

[1] Van Der Horst C,Martinez PF, Seif C, Groth W, Jünemann KP. Male genital injuries: diagnostics and treatment. BJUI. 2004; 93( 7): $927-930$

[2] Waxman S, Beekley A, Morey A, Soderdahl D.Penetrating trauma to the external genitalia in Operation Iraqi Freedom.International Journal of Impotence Research. 2009; 21(2): 145-148.

[3] Brandes SB, Buckman RF, Chelsky MJ, Hanno PM. External genitalia gunshot wounds: a ten-year experience with fifty-six cases. J Trauma. 1995; 39(2): 266- 271.

[4] Archbold JA, Barros d'sa AA, Morrison E.Genito-urinary tract injuries of civil hostilities. Br J Surg. 1981; 68(9): 625-631.

[5] Marekovic Z, Derezic D, Krhen I, Kastelan Z. Urogenital war injuries.Mil Med. 1997; 162(5): 346-348

[6] Monga M, Hellstrom WJ.Testicular trauma.Adolesc Med. 1996; 7(1): 141-148.

[7] Merck.(2007). Merck manual.http://www.merck.com/mmpe/sec21/ch314/ch314c.html.

[8] Wessells H, Long L. Penile and genital injuries. Urol Clin North America. 2006; 33(1): 117-26.

[9] Lee SH, Bak CW, Choi MH, Lee HS, Lee MS, Yoon SJ. Trauma to male genital organs: A 10-year review of 156 patients, including 118 treated by surgery. BJU International. 2008; 101(2): 211-215.

[10] Ahmed A, Mbibu NH.Aetiology and management of injuries to male external genitalia in Nigeria.Injury. 2008; 39(1): 128-133.

[11] Mohr AM, Pham AM, Lavery RF, Sifri Z, Bargman V, Livingston DH. Management of trauma to the male external genitalia: The usefulness of the American association for the surgery of trauma organ injury scales. The journal of urology. 2003; 170(6): 23112315.

[12] Bertini JE, Corriere JN.The etiology and management of genital injuries.Journal of Trauma-Injury. 1988; 28(8): 1278-1281.

[13] Kunkle DA, Lebed BD, Mydlo JH, Pontari MA. Evaluation and management of gunshot wounds of the penis: 20 -year experience at an urban trauma center. J Trauma. 2008; 64(4): 1038-1042.

[14] Mansi MK, Emran M, el-Mahrouky A, el Mateet MS. Experience with penile fractures in Egypt. Long term results of immediate surgical repair. J Trauma. 1993; 35(1): 67-70

[15] Redman JF, Miedema EB. Traumatic rupture of the corpus cavernosum: A case report and survey of the incidence in Arkansas. $J$ Urol. 1981; 126(6): 830-831.

[16] Kibria SA, Islam MF, Bhuyan ZI. Fracture penis - A study of twenty cases. Bangladesh Med Res Counc Bull. 2001; 27(1):33-37.

[17] Karadeniz T, Topsakal M, Ariman A. Penile fracture. Differential diagnosis, management and outcome. Br J Urol. 1996; 77(2): 279-281.

[18] Fergany AF, Angermeier KW, Montague DK. Review of Cleveland Clinic experience with penile fracture. Urology. 1999; 54(2): $352-355$.

[19] Adigun IA, Kuranga SA, Abdulrahman LO.Grinding machine: Friend or foe. West African Journal of Medicine. 2002; 21(4): 338340

[20] McAninch JW,Kahn RI, Jeffrey RB.Major traumatic and septic genital injuries.J Trauma. 1984; 24(4): 291-298.

[21] Jezior JR, J.D. Brady JD and S.M. Schlossberg SM. Management of penile amputation injuries. World J Surg. 2001; 25(12): 1602 1609.

[22] Cass AS.Testicular trauma. J Urol.1983; 129(2): 299-300.

[23] Morey AF, Metro MJ, Carney KJ, Miller KS, McAninch JW. Consensus on genitourinary trauma: External genitalia. BJU International. 2004; 94(4):507-515. 